Sex- and age- dependent effect of pre-gestational chronic stress and mirtazapine treatment on neurobehavioral

\title{
development of offspring
}

Viñas-Noguera Mireiaa,b*, Csatlósová Kristína ${ }^{a, c}$, Šimončičová Evad, Bögi Ezstera, Ujházy Eduarda, Dubovický

9 dDivision of Medical Sciences, University of Victoria, Victoria, BC, Canada

\section{*Corresponding Author}

\section{ABSTRACT}

21 health concern for both the mother and the child, due to the consequences of treatment in terms of the reliability

22 and safety for the proper neurodevelopment of the organism being not well known. Atypical antidepressants, such

23 as mirtazapine, that targets both serotonergic and noradrenergic systems in the central nervous system (CNS), 
24 represent a novel focus of research due to its unique pharmacological profile. The aim of this work was to study

25 the effects of maternal depression and/or perinatal antidepressant mirtazapine treatment on the neurobehavioral development of the offspring. Pre-gestationally chronically stressed or non-stressed Wistar rat dams were treated with either mirtazapine $(10 \mathrm{mg} / \mathrm{kg} /$ day) or vehicle during pregnancy and lactation followed by analysis of offspring's behavior at juvenile and adolescent age. We found mirtazapine induced alterations of nursing behavior. In offspring, pregestational stress (PS) had an anxiogenic effect on adolescent males and increased their active behavior in forced swim test. Interaction between pregestational stress and mirtazapine treatment variously induced anxiolytic changes of juvenile and adolescent females and impairment of spatial memory in adolescent females as well. Hippocampal density of synaptophysin, pre-synaptic protein marker, was decreased mainly by mirtazapine treatment. In conclusion, our results show mirtazapine induced alterations in maternal behavior and several sex- and age-dependent changes in neurobehavioral development of offspring caused by both prenatal mirtazapine treatment and/or chronic pregestational stress. synaptophysin

\section{INTRODUCTION} periods of hormonal fluctuation, such as the perinatal period $(2,3)$. Perinatal depression has been reported to exert a negative impact in children neurodevelopment, becoming a risk factor in developing neuropsychiatric disorders

$44(4-6)$ Second generation antidepressants (SGA), such as selective serotonin reuptake inhibitors (SSRIs) (fluoxetine, sertraline) or serotonin-norepinephrine reuptake inhibitors (SNRIs) (venlafaxine) introduced in Europe in the 1980s,

47 are recorded as the first line antidepressant treatment during pregnancy by most medication guides $(7,8)$. The World 
main concern for specialists is the impact of the treatment on the developing fetus/child, namely risk of potential congenital malformations, neonatal withdrawal symptoms or poor neonatal adaptation syndrome as well as longterm neurodevelopmental consequences (10-13). In addition, the delay in treatment efficacy and the presence of many side effects lead researchers to investigate alterative antidepressants with better efficacy, faster onset of action and lesser counterproductive reactions.

Mirtazapine (MIR) (Fig 1) has a tetra-cyclic chemical structure with molecular weight of 265.36 and belongs to the piperazino-azepine group of compounds. It is a new generation antidepressant that has a different mechanism of action than SGAs, targeting both the serotonergic and noradrenergic systems in the CNS. It is a noradrenaline (NE) and specific serotonin (5-HT) antidepressant (NaSSA) that acts as an antagonist at central a2-adrenergic inhibitory autoreceptors and heteroreceptors, as well as at the $5-\mathrm{HT}_{2}$ and $5-\mathrm{HT}_{3}$ receptors. MIR enhances the release and availability of NE by blocking presynaptic inhibitory $\alpha 2$-autoreceptors and enhances the 5 -HT release by antagonism of the $\alpha 2$-heteroreceptors in the serotonergic nerve terminals and simultaneously blockade of postsynaptic $5-\mathrm{HT}_{2}$ and $5-\mathrm{HT}_{3}$ receptors. Thanks to this double activity, MIR is suggested to induce earlier onset of antidepressant effects avoiding the serotonergic related side effects such as high body temperature, agitation, increased reflexes, tremor, sweating, dilated pupils, and diarrhea (14). However, it may induce an enhanced body weight gain and sleepiness $(15,16)$. Mirtazapine has low in vitro affinity for central and peripheral dopaminergic, cholinergic, and muscarinic receptors, but high affinity for central and peripheral histamine $\mathrm{H} 1$ receptors. However, it appears that the antihistaminergic effects of the drug are counteracted by noradrenergic transmission when the drug is commenced at dosages $\geq 15 \mathrm{mg} /$ day, i.e. within the recommended dosage range (17). Initial dose of MIR is $15 \mathrm{mg} /$ day orally once a day at bedtime and maintenance dose represents 15 to $45 \mathrm{mg}$ orally once a day (18). Even though MIR seems to represent a plausible alternative of antidepressant medication during gestation and there is no evidence that use of mirtazapine in pregnancy causes birth defects, preterm birth, or low infant birth weight. While the evidence for

71 other pregnancy outcomes is also reassuring, only small numbers of women have been studied and number of 72 animal studies is not sufficient (19).

73 Despite lacking efficient translatability, several animal models, including chronic unpredictable stress, have been 74 investigated for decades to evaluate depression-like behavioral changes and their potential mechanisms of action. 
Studies in rodents show that chronic pre-gestational and prenatal maternal stress, which disrupt the maternal endocrine, nervous and immune systems, can induce long-term alterations in the synaptic structure and so impact the behavioral outcomes in the offspring $(6,20)$. Prior to regulatory roles of serotonin, norepinephrine and dopamine neurotransmitters in adult brain, monoamines play an important role in the fetal maturation of the brain, such as during neuronal proliferation, migration and differentiation, myelinization and synaptogenesis (21). The exposure to stressful situations early in life may disable the optimal structural and functional development of hippocampus, due to the damaging action of excessive corticosterone concentration and dysregulation of monoamines $(11,22)$. Persisting high levels of stress are thought to result in loss of synapses in circuits underlying affective and cognitive processes. These reductions are presumed to contribute to the symptoms of depression associated with major depressive disorder (23). Synaptophysin is a synaptic vesicle glycoprotein, which immunoreactivity is present in a punctate pattern in the hippocampus and has been used as a presynaptic marker for quantification of synapses (24). The hippocampal formation consists of several histologically distinguishable modules, such as Cornu Ammonis (CA) regions (CA1, CA2, CA3, CA4), dentate gyrus (DG), presubiculum, and subiculum. These regions of the hippocampus are associated with different functions (e.g. memory encoding and retrieval) and may be specifically disrupted in various diseases (25). Granule cells, the main output cells of the DG, send axons (mossy fibers) through CA4 to CA3 and innervate a small number of pyramidal cells and a disproportionally large number of interneurons CA3 pyramidal cells then form recurrent excitatory network and send axons to CA1. Theoretical work, as well as anatomical, physiological, and behavioral experiments support the idea that the DG-CA3 system performs the pattern separation and the pattern completion of the inputs to the hippocampus, operations needed for memory encoding and retrieval (26). Purpose of the hippocampus happens to be severely affected by early life stress, predisposing the individual to an impaired reactivity when exposed to adverse environmental stimuli (27). In our previous study, we have shown that pre-gestational maternal stress may affect hippocampus at the time of birth by increasing the resting membrane potential, suppressing depolarization-activated action potential firing, and increasing the spontaneous activity of hippocampal cells from newborn rat offspring (28), but pre-gestational stress induced changes in different subregions of hippocampus are not thoroughly known. However, antidepressant treatment may facilitate the challenged neurogenesis by, upregulating the hippocampal concentration of glucocorticoid receptors, which help to attenuate the hyperactivity of the HPA axis and inducing morphological changes in the neuronal network $(11,27,29)$. 
Some studies suggest that developmental fluoxetine (SSRI) exposure of prenatally stressed male and female offspring reversed the effect of stress on the number of immature neurons in the dentate gyrus (DG), with effects being more prevalent in adult male offspring $(30,31)$. However, knowledge of mirtazapine treatment's impact on pregnancy and lactation hippocampal neurogenesis of juvenile, adolescent and adult offspring during last days of pregnancy and for following 2 weeks postpartum (PP), is very limited.

107 The aim of the present study was to determine the possible implications that pre-gestational chronic stress have on the behavioral and neurodevelopmental outputs in the offspring of both sexes during juvenile and adolescent age and to investigate the consequences of administration of the new generation antidepressant mirtazapine on these variables aiming our focus on functional brain developments that starts day 10 PP (32-35).

MATERIALS AND METHODS

\section{Animal breeding}

114 Female nulliparous Wistar rats (initial weight 200-220 g, age 2-3 months, $n=44$ ) used in this study were obtained

115 from the Department of Toxicology and Laboratory Animal Breeding Station of the Institute of Experimental

Slovak Republic. After 7 days of acclimatization, females were randomly assigned to stress or non-stress groups.

Animals in the stress group were exposed to unpredictable stressors of mild intensity for a total of 3 weeks. One

119 week after the end of the stress procedure, females were mated with males in the ratio 3:1. The presence of 120 spermatozoa in vaginal smears was considered day 0 of gestation. On day 15 of gestation, the females were 121 separated and housed individually. The animals had ad libitum access to food pellets and water and were kept in a 122 temperature and humidity-controlled room $\left(20-24^{\circ} \mathrm{C}\right.$ and relative humidity $\left.50-60 \%\right)$ with $12 / 12$ hours of light/dark 123 cycle. The experiments were conducted in compliance with the Principles of Laboratory Animal Care issued by the 124 Ethical Committee of the Institute of Experimental Pharmacology and Toxicology, Slovak Academy of Sciences, 125 Bratislava, and the experimental design was approved by the State Veterinary and Food Administration of the Slovak Republic. 
127 One day after birth, litters were culled to four males and four females (with eight offspring per cage). Reproductive

128 variables were recorded right after the birth. The offspring were weaned on post-partum day 21 and housed in litter

129 groups of same-sex four animals per cage. No more than two pups from the same mother per group ( $n=6-8$

130 animals/group) were used for behavioral testing.

\section{Chronic unpredictable stress schedule}

132 In order to not expose females to stressors during pregnancy but rather study ongoing effects of chronic stress,

133 females were assigned to stress or non-stress groups prior to breeding (Fig 2). The animals were exposed to 1-2

134 stressors per day. The list of stressors included: 1) Overcrowding - 6 rats housed together (24h); 2) Exposure to damp

135 bedding (12h); 3) Food deprivation (24h); 4) Predator stress - cloth with cat odor (10h); 5) Water deprivation (12h);

136 6) Cage decline at 45 -degree angle (6h); 7) Strobe light- flicker lights (12h).

\section{Mirtazapine treatment}

138 Mirtazapine (Mikrochem Trade spol. s r.o.) with a molecular weight of 265.36 was diluted in citric acid and

139 administered orally via the wafer biscuit (size of $1 \mathrm{~cm}^{3}$ ) to pregnant rats from day 10 of gestation until sacrifice at

140 the clinically relevant dose of $10 \mathrm{mg} / \mathrm{kg}$ once per day. Pups were receiving mirtazapine via mother until weaning on

141 day 21 post-partum (PP). This dose was chosen based on a body surface area normalization (BSA) conversion used

142 to determine the starting human dose extrapolated from animal studies. The Km factor, which is the ratio of body

143 weight $(\mathrm{kg})$ to body surface area $\left(\mathrm{m}^{2}\right)$, is used to convert doses expressed in $\mathrm{mg} / \mathrm{kg}$ to units of $\mathrm{mg} / \mathrm{m}^{2}(36)$. Dose 10

$144 \mathrm{mg} / \mathrm{kg}$ a day was used to simulate low dose end in humans. The dams from control groups received $1 \mathrm{~cm}^{3}$ of wafer

145 biscuit once a day filled with vehicle (water). Feeding was completed under investigator's supervision to ensure the

146 dam consumed the entire biscuit. Pregnant dams were randomly divided into 4 groups: non-stress + VEHIC (vehicle),

147 non-stress + MIR, stress + VEHIC, stress + MIR.

\section{Rat Grimace Scale}

149 Mothers were placed in individual cages for 10 min and each minute 4 pictures were taken from each rat from front

150 with a Nixon professional camera. Animals were tested 5 weeks after CUS. Each picture was evaluated by a score

151 from 0 to 2 according to the following four action units (37): 

closure or squeezing.

154 2. Nose/cheek flattening: less bulging of nose and cheek and absence of crease between cheek and whisker pads.

3. Ear changes: ears in pain tend to fold, curl and angle forwards or outwards, and the space between ears is wider.

4. Whisker change: whiskers move forward (away from face) and tend to bunch.

\section{Behavioral tests}

\section{Maternal behavior}

159 Mothers were observed for 5 consecutive days from PD2 until PD6 two times per day for 5 min based on previous 160 literature (20). Observations took place in the morning (between 8:30 a.m. and 10.00 a.m.) and the afternoon 161 (between 2:30 p.m. and 3:30 p.m.). Time and number of bouts in the following maternal behaviors were recorded:

162 licking; licking/nursing; nursing (arched-back nursing, blanket nursing, and/or passive nursing); nest building and 163 time off the pups. Differences between groups in maternal behaviors were assessed using total time spent in these 164 maternal behaviors.

\section{Forced swim test (FST)}

The FST consists of a container filled with water where the animal is placed and cannot escape. The apparatus consists of a vertical cylindrical glass container (height $45 \mathrm{~cm}$, diameter $25 \mathrm{~cm}$ ) filled with tap water at $23 \pm 1^{\circ} \mathrm{C}$. The water volume is enough to ensure that the animals can not touch the bottom of the container with their hind paws. The forced swim test was conducted over two days. On the first day, rats were introduced to the cylindrical glass tank filled with water for $15 \mathrm{~min}$ (not videotaped), towel-dried and returned to their home cage. Twenty-four hours

171 later, the animals were exposed to the same experimental conditions for $5 \mathrm{~min}$, dried and returned to their home 172 cage. Sessions were videotaped and scored using the software ANYMAZE ${ }^{\mathrm{TM}}$ (Stoelting Europa, Co., Ireland). All tests 173 were carried out between 8:00 a.m. to 12:00 p.m. The behavior scored in the forced swim test concerns: (1) 174 immobility- floating with the absence of any movement, (2) latency to be immobile- time duration, (3) swimming,

175 (4) climbing. Offspring was tested at the age of 48 days.

\section{Elevated plus maze (EPM)}

177 All parts of the apparatus are made of dark polyvinyl plastic. The open and the closed arms of the maze are $50 \mathrm{~cm}$ above the floor, $50 \mathrm{~cm}$ long and $10 \mathrm{~cm}$ wide. Two tests were running simultaneously. The movements of the rats were 
tracked with digital camera and the individual sessions were analyzed by computer software ANYMAZETM (Stoelting time spent in the open arms of the elevated plus maze. The animals were tested at the age of 27 and 47 days.

\section{Y-Maze}

186 The Y-Maze Test is widely used to assess exploratory behaviors, learning, and memory function in rodents and short-

187 term memory (38). The apparatus was made from black Plexiglas $(50 \times 16 \times 32 \mathrm{~cm})$ in which the arms were the home cage for one minute and the maze was cleaned with $70 \%$ ethanol. The second trial lasted 5 minutes with animal having the access to all three arms. Sessions were videotaped and scored using the software ANYMAZE ${ }^{\mathrm{TM}}$ (Stoelting Europa, Co., Ireland). All tests were carried out between 8:00 a.m. to 12:00 p.m. under dim light condition. calculated by dividing the number of alternations by number of possible triads $x 100$ ) is considered to reflect spatial working memory, while the total number of arm entries was considered to reflect spontaneous locomotor activity

$197(39,40)$.

\section{Immunohistochemistry assay}

199 Collection of tissue from offspring was executed at different ages of the animals: in juvenile age (PP31) and in adolescent age (PP50). The animals were killed by cervical dislocation. Brains were extracted (not perfused) and post-fixed with $4 \%$ paraformaldehyde for $24 \mathrm{~h}$, cryoprotected in $30 \%$ sucrose/phosphate-buffered saline solution for up to 1 week, rapid frozen with liquid nitrogen and kept at $-80^{\circ} \mathrm{C}$. Before immunohistochemistry assay, brain tissue was sliced in $40 \mu \mathrm{m}$ sections on a cryostat (Leica). Tissue sections were stored in antifreeze solution at $-15^{\circ} \mathrm{C}$. The 
207 Buffered Saline Tween at room temperature for $30 \mathrm{~min}$ to decrease probability of non-specific antibody binding, followed by overnight incubation at $4^{\circ} \mathrm{C}$ in mouse anti-synaptophysin (1:200, Sigma Aldrich). Sections were then incubated at room temperature for $2 \mathrm{~h}$ in biotinylated goat anti-mouse (1:200, Vector Laboratories). Brain sections were further processed using the Avidin-Biotin Complex (ABC Elite kit; 1:1000; Vector laboratories) and DAB kit

211 (Vector laboratories). Sections were mounted on Starfrost Advanced Adhesive for IHC (Bamed) dried, dehydrated 212 and coverslipped with Permount (Fisher Scientific).

\section{Quantification}

214 Sections of the dorsal hippocampus were analyzed for optical densities of synaptophysin. Immunoreactivity for all 215 sections was examined under 40x objective using Leica DM4000M. Photomicrographs were taken for three areas 216 within each analyzed hippocampal region, i.e., CA3, CA4 and DG. The software ImageJ64 (Wayne Rasband, NIH,

217 Bethesda MD, USA) was used for assessment of optical densities for all immunoreactive cells. The relative optical 218 density was defined as the difference in optical density (grey level) after calibration between the area of interest 219 and the background, which was an equivalent area adjacent to the area of interest with minimal staining.

\section{Data analysis}

221 Normality of data was analyzed by Shapiro-Wilks test. Data without normal distribution were analyzed using Kruskal-

222 Wallis test (STATISTICA 10). Analysis of variance (factorial ANOVA) was used to evaluate differences in the individual 223 variables of tests with normally distributed data (STATISTICA 10). Post-hoc comparisons utilized the Tukey HSD test $224(p \leq 0.05)$. The data were expressed as mean \pm standard error mean (S.E.M). The changes with values of $p \leq 0.05$ were 225 considered statistically significant. All analysis was done in a blind manner.

\section{RESULTS}

\section{MOTHERS}


Rat grimace test scores has been used to evaluate spontaneous pain (41). We observed significant main effect of stress on grimace test scores $(F(1,22)=5.00 ; p \leq 0.05)$. Post-hoc analysis did not reveal any significant differences

232 (Fig 3).

Maternal behavior

There was no significant main effect of stress or mirtazapine on total time dams spent nursing (Fig 4A), however, we observed significant main effect of mirtazapine on the percentage of passive nursing and blanket nursing $(F(1,30)=$ $10.74 ; p \leq 0.01)$. Subsequent post-hoc analysis showed decrease of passive nursing ( $\leq \leq 0.05)$ and increase of blanket nursing $(p \leq 0.05)$ in stress $\times$ vehicle group as compared to both mirtazapine groups (Fig 4B).

\section{OFFSPRING}

\section{Elevated plus maze- juvenile offspring}

We did not observe an effect of sex but there was a stress $\times$ mirtazapine interaction in females on percentage of distance travelled in the open $(F(1,24)=4.89 ; p \leq 0.05)$ (Fig $5 A)$ and closed arms $(F(1,24)=7.82 ; p \leq 0.01)(F i g 5 B)$ of EPM, an effect was not present in male offspring. Further analysis showed a decrease in total distance travelled in

243 stress $\times$ vehicle females compared to control group.

\section{Elevated plus maze- adolescent}

245 Main effect of sex was present in all parameters of elevated plus maze with females being more active (higher total 246 distance travelled) than males $(F(1,62)=9.04 ; p \leq 0.01)$.

247 In males, we observed marginally significant main effect of stress $\times$ mirtazapine interaction in total distance travelled

$248(F(1,30)=3.69 ; p=0.06)$. Post-hoc analysis showed significantly decreased total distance travelled in stress $\times$ vehicle group $(p \leq 0.05)$ compared to non-stress $\times$ vehicle group. Also, trend for decrease in non-stress $\times$ mirtazapine $(p=0.07)$ and stress $\times$ mirtazapine $(p=0.07)$ groups compared to non-stress $\times$ vehicle group (Fig $6 A)$ was present. In females, we did not observe any differences in total distance travelled (Fig 6A).

252 In males, there were no changes in the percentage of time spent in the open arm (Fig 6B) but we observed a main 253 effect of stress $(F(1,30)=4.53 ; p \leq 0.05)$ in the percentage of time spent in the closed arm and trend for stress $x$ 
mirtazapine interaction $(1,30)=3.37 ; p=0.07)$. Post-hoc analysis revealed that animals from stress $\times$ vehicle group had significantly increased percentage of time spent in the closed arm compared to non-stress $\times$ vehicle group $(p \leq 0.05)$ (Fig 6C).

In females, we observed marginally significant effect of mirtazapine $(F(1,32)=3.70 ; p=0.06)$ and a trend in effect of stress $(F(1,32)=3.06 ; p=0.08)$ on the percentage of time spent in the open arm. Post-hoc analysis revealed only marginally significant increase in stress $\times$ mirtazapine group compared to non-stress $\times$ vehicle group $(p=0.06)$ (Fig $6 B)$. There was marginally significant main effect of stress $\times$ mirtazapine interaction $(F(1,32)=3.53 ; p=0.06)$ in the percentage of time spent in the closed arm. Post-hoc analysis showed decrease in stress $\times$ mirtazapine group significant compared to non-stress $\times$ vehicle $(p \leq 0.05)$ and non-stress $\times$ mirtazapine group $(p \leq 0.05)$ a trend in decrease compared to stress $\times$ vehicle group $(p=0.08)$ (Fig $6 C)$.

\section{Forced swim test}

There were no sex differences in either of the selected forced swim test parameters.

Kruskal-Wallis test showed significant main effect of stress in time spent floating (males: $H=7.41 ; p \leq 0.01$; females:

(males: $\mathrm{H}=6.49 ; \mathrm{p} \leq 0.01$; females: $\mathrm{H}=10.24 ; \mathrm{p} \leq 0.001$ ). Further analysis revealed that floating time of stress $\times$ 7B). Climbing time was not significantly changed between individual groups in either sex (Fig 7C).

275 We observed main effect of sex in both motor activity $(F(1,45)=11.53 ; p \leq 0.01)$ as well as in percentage of spontaneous alterations $(F(1,45)=4.27 ; p \leq 0.05)$ with females being more active but having decreased percentage of spontaneous alterations compared to males. 
278 In males, a significant main effect of treatment $(F(1,20)=9.79 ; p \leq 0.01)$ was observed in total distance travelled.

279 Post-hoc analysis revealed marginally significant decrease in non-stress $\times$ mirtazapine group compared to non-stress

$280 \times$ vehicle group $(p=0.07)$ and significant decrease compared to stress $\times$ vehicle group ( $p \leq 0.05)($ Fig $8 A)$. We did not

281 observe any significant changes percentage of spontaneous alterations (Fig 8B).

282 In females, a significant main effect of stress was in total distance travelled $(F(1,25)=4.95 ; p \leq 0.05)$. Post-hoc 283 analysis showed marginally significant increase of horizontal motor activity in stress $\times$ mirtazapine group compared 284 to non-stress $\times$ vehicle group $(p=0.07)$ (Fig 8A). Further, we observed significant main effect of mirtazapine $(F(1,25)$ $=11.25 ; \mathrm{p} \leq 0.01)$ and mirtazapine $\times$ stress interaction $(F(1,25)=7.81 ; p \leq 0.01)$ in percentage of spontaneous alterations. Post-hoc analysis revealed significant or marginally significant decrease in all groups (non-stress $\times$ mirtazapine $p \leq 0.01$; stress $\times$ vehicle $p \leq 0.06$; stress $\times$ mirtazapine $p \leq 0.05$ ) compared to non-stress $x$ vehicle group (Fig 8B).

Synaptophysin-juvenile

We did not observe any statistically significant changes in the synaptophysin optical density in the hippocampal areas Ca3, Ca4 and dentate gyrus (data not shown).

\section{Synaptophysin-adolescent}

We found significant main effect of sex present only in area Ca4 of hippocampus $(F(1,47)=7.23 ; p \leq 0.01)$ (Fig $9 A)$. Further, we observed significant main effect of mirtazapine in hippocampal areas Ca3 $(F(1,19)=9.01 ; p \leq 0.01)$ (Fig $9 B)$ and $\mathrm{Ca} 4(\mathrm{~F}(1,23)=5.87 ; \mathrm{p} \leq 0.05)(\mathrm{Fig} 9 \mathrm{C})$ of females. Post-hoc analysis did not reveal significant differences between groups.

\section{DISCUSSION}

299 In the present study, focused on possible implications of pre-gestational chronic stress on the neurodevelopmental 300 and behavioral outputs in the offspring of both sexes during juvenile age and adolescence, we wanted to investigate 301 the consequences of administration of the atypical antidepressant mirtazapine. 
We evaluated the spontaneous pain of the mothers by the Rat Grimace Scale (RGS) and we found increased facial acute and inflammatory pain but it can be applied to a wider range of pain types and chronicity $(42,43)$ and this is supported by our data that suggest ongoing influence of CUS even 5 weeks after the CUS procedure. to blanket nursing favoring the latter one, indicating a slight influence of mirtazapine on some aspects of maternal behavior. Mirtazapine acts by antagonizing the adrenergic alpha2-autoreceptors and alpha2-heteroreceptors as well as by blocking 5-HT2 and 5-HT3 receptors. It enhances, therefore, the release of norepinephrine and 5-HT1Athus suppose that serotonin activity of MIR can underlie these changes. Shift in maternal behavior in favor of more active blanket nursing caused by antidepressant treatment is in line with our previous results from venlafaxine (serotonin-norepinephrine reuptake inhibitor) (49) as well as results from fluoxetine (selective serotonin reuptake inhibitor) (50).

\section{Anxiety-like behavior}

Offspring of mothers that have experienced stress during gestation may have impaired emotional development due to a dysregulation of the HPA axis, leading to a higher risk of developing a cognitive and/or mood disorders in adulthood (28,51-53). We evaluated the effect of pregestational stress (PS) exposure on intensity of anxiety-like behavior by the elevated plus-maze test, a validated behavioral paradigm based on rodent's preference of closed to open spaces, with latter presenting a significant anxiety-like behavior inducing condition (54). expected due to unmature reproductive system (55). However, female offspring of stressed untreated mothers exhibited decreased anxiety-like behavior that was not present if mothers were treated with MIR. This was changed in adolescence, when females showed decreased anxiety-like behavior if mothers were stressed and treated with MIR. Different results were observed in adolescent male rats, who displayed decreased anxiety-like behavior due to 
behavior, due to maternal stress, were previously described by several research groups $(28,56)$. Although there are animals spent less time in the open arm, albeit sex was not distinguished (61). Nevertheless, the sex-dependent differences in adaptive behavioral performance to a challenge due to maternal stress may be explained by the influence of individual fetal brain programming, differentially modulating e.g. the responsiveness to a new stimuli, or a hormone arousal during adolescence (62). Recent studies postulate that the sexual hormones, testosterone and ground for further investigation.

\section{Depressive-like behavior}

344 Modified forced swim test, based on the protocol established by Porsolt (64), has been used as a tool to determine the learned helplessness (rodent despair) and therapeutic efficacy of mirtazapine. However, several recent studies postulate that the immobility in this test may not be a sign of a depressive-like state but rather reflection of the individual ability to cope with an acute stressor, explaining the passive phenotype as a result of animal's difficulties to adapt to external stimuli $(65,66)$.

Our results show an increased active behavior of animals from stressed mothers of both sexes regardless of mirtazapine treatment manifested as less time floating and more time trying to actively escape. Even though several studies declared increased immobility time in animals that have experienced stress during their lives, particularly prenatally, $(52,67,68)$ there are studies showing possibility of prenatal stress inducing adaptive changes contributing

353 to stress resilience later in life (69-71). Active behaviors, such as swimming and climbing, in the rat forced swimming 
modulated by serotonergic neurotransmission, as Brummelte and colleagues demonstrated a decreased swimming of offspring whose mothers were exposed to high levels of corticosterone while pregnant (73). Also, Vázquez et al. suggested that increased levels of serotonin in control animals after FST may be responsible for shorter time spent immobile and increased time spent swimming, corroborating an effect of the serotonergic system, which in turn modulates dopaminergic projections associated with the reward system and the coping with stress. In this terms, lower levels of serotonin were linked to a stress-induced anhedonic state, while higher levels promote a nonanhedonic state (52). Accordingly, higher levels of serotonin may be a plausible explanation to our results.

We encountered sex-dependent differences in the Y-maze, a behavioral paradigm set to assess the spatial memory performance building on the natural inclination of rodents to explore new environments. Male offspring from mirtazapine treated mothers showed reduced locomotive activity, indicating an influence of treatment on executive capacity. On the other hand, females seemed to be rather affected by the pregestational stress experience of the mothers, which induced a hyperactivity-like response. Such a result may be reflective of hyperactivity or even ADHD described in children of stressed mothers while pregnant $(74,75)$. However, sex differences in reactivity to either pre-gestational stress or perinatal mirtazapine treatment related to potentially hyperactive behavior require further investigation. In children, PS is connected to cognitive, behavioral, and emotional problems such autism and ADHD

$371(76,77)$. The maternal stress, manifesting as increased cortisol and corticotropin-releasing factor (CRF) levels, affects

372 the fetal development by reprogramming the HPA axis, leading to impaired memory and learning due to the long-

373 lasting effects in the hippocampus (78). Moreover, Deminière et al. had previously described an increased locomotor

374 reactivity to novelty in litters of pre-gestationally stressed mothers, which authors associated with a modified dopaminergic activity in the prefrontal cortex and nucleus accumbens (79). Experience-dependent plasticity of hippocampal neurons and adult neurogenesis, processes of importance for optimal learning or memory formation and processing, are modulated through epigenetic mechanisms, which induce long-lasting changes determining the ability of individuals to cope with adverse situations $(80,81)$. 
not present in males. Conrad et al. studied the effects of chronic stress on spatial memory performance of adult rats them more vulnerable and unpredictable to external influences (86-88).

\section{Synaptophysin analysis}

Synaptophysin is used as a marker of synaptic plasticity and synaptic nerve terminal density (89). We analyzed optical density (OD) of synaptophysin, a calcium-binding glycoprotein widely distributed in the presynaptic vesicle membrane, that is required for vesicle fusion and neurotransmitter release, in the CA3, CA4 and DG areas of the hippocampus. Results of synaptophysin density in our study were age-dependent with no changes in juvenile offspring. However, with onset of adolescence we observed prominent effect of sex with synaptophysin OD males remaining intact under all conditions while females being influenced by maternal mirtazapine treatment. This effect was regionally specific as changes were observed only in CA3 and CA4 areas but not in DG. Sex differences can be seen in the neural plasticity at DG-CA3 synapses. In short, mossy fibers evoke larger population spikes in CA3 stronger synaptic connections to CA3 neurons than females (90). Limitation of our study is that we didn't evaluate estrus cycle phase before extraction of the brains. There is very limited research available on maternal 

developing brain (94) explaining the differential effect of stress on limbic synaptic plasticity in female rats. However, there are differences between our study compared to studies previously mentioned. Our model comprises of CUS prior to gestation and we tested the offspring in adolescent age, when the reproductive system of the offspring is not fully developed, so we can't rule out other stress related changes in later life that were not seen in this study.

\section{CONCLUSIONS}

417 Neurobiology of depression remains mostly unexplained with several theories trying to identify its etiology including

418 the impairment of monoaminergic systems coupled with an altered neural plasticity, dysregulation of the HPA axis

419 or the immunological response. Maternal depression as well as antidepressant treatment thus may lead to a broad

420 spectrum of neurodevelopmental changes in the offspring. Our results suggest mirtazapine induced alterations in

421 maternal behavior and several sex- and age-dependent changes in neurobehavioral development of offspring caused

422 by either or combination of prenatal mirtazapine treatment and chronic pre-gestational stress.

\section{ACKNOWLEDGMENTS} 19-0435). The authors confirm that there is no conflict of interest.

\section{REFERENCES}

429 1. Slavich GM, Sacher J. Stress, sex hormones, inflammation, and major depressive disorder: Extending Social Signal Transduction Theory of Depression to account for sex differences in mood disorders. 
2. Pawluski JL, Császár E, Savage E, Martinez-Claros M, Steinbusch HWM, van den Hove D. Effects of stress early in gestation on hippocampal neurogenesis and glucocorticoid receptor density in pregnant rats. Neuroscience. 2015;290:379-88.

3. Liu J, Meng F, Dai J, Wu M, Wang W, Liu C, et al. The BDNF-FoxO1 Axis in the medial prefrontal cortex modulates depressive-like behaviors induced by chronic unpredictable stress in postpartum female mice. Mol Brain. 2020;13(1):1-14.

4. Kiryanova V, Meunier SJ, Vecchiarelli HA, Hill MN, Dyck RH. Effects of maternal stress and perinatal fluoxetine exposure on behavioral outcomes of adult male offspring. Neuroscience. 2016;320:281-96.

5. Gustafsson HC, Sullivan EL, Nousen EK, Sullivan CA, Huang E, Rincon M, et al. Maternal prenatal depression predicts infant negative affect via maternal inflammatory cytokine levels. Brain Behav Immun.

6. Mandolini GM, Lazzaretti M, Delvecchio G, Bressi C, Soares JC, Brambilla P. Association between serum BDNF levels and maternal perinatal depression: A review: Special Section on "Translational and Neuroscience Studies in Affective Disorders" Section Editor, Maria Nobile MD, PhD. J Affect Disord.

7. Bénard-Laribière A, Pambrun E, Sutter-Dallay AL, Gautier S, Hurault-Delarue C, Damase-Michel C, et al. Patterns of antidepressant use during pregnancy: a nationwide population-based cohort study. Br J Clin Pharmacol [Internet]. 2018 Aug 1 [cited 2021 Jun 15];84(8):1764-75. Available from:

8. Molenaar NM, Kamperman AM, Boyce P, Bergink V. Guidelines on treatment of perinatal depression with antidepressants: An international review [Internet]. Vol. 52, Australian and New Zealand Journal of

9. Depression [Internet]. [cited 2021 Jun 15]. Available from: https://www.who.int/news-room/factPsychiatry. SAGE Publications Inc.; 2018 [cited 2021 Jun 15]. p. 320-7. Available from: /pmc/articles/PMC5871019/

10. Czarzasta K, Makowska-Zubrycka M, Kasarello K, Skital VM, Tyszkowska K, Matusik K, et al. A rat model to study maternal depression during pregnancy and postpartum periods, its comorbidity with cardiovascular treatment with sertraline and its discontinuation in an animal model of maternal depression. Behav Brain Res. 2019;366(February):1-12. 
12. Uguz F. Short-Term Safety of Paroxetine Plus Low-Dose Mirtazapine during Lactation. Breastfeed Med. 2019;14(2):131-2.

13. Wikenius E, Myhre AM, Page CM, Moe V, Smith L, Heiervang ER, et al. Prenatal maternal depressive symptoms and infant DNA methylation: a longitudinal epigenome-wide study. Nord J Psychiatry. 2019;73(4-5):257-63.

14. Volpi-Abadie J, Kaye AM, Kaye AD. Serotonin syndrome. Ochsner J. 2013;13(4):533-40.

15. Anttila SAK, Leinonen EVJ. A review of the pharmacological and clinical profile of mirtazapine. CNS Drug Reviews Neva Press Inc.; 2001 p. 249-64.

16. Fawcett J, Barkin RL. Review of the results from clinical studies on the efficacy, safety and tolerability of mirtazapine for the treatment of patients with major depression. J Affect Disord. 1998;51(3):267-85.

17. Holm KJ, Markham A. Mirtazapine: A review of its use in major depression. Drugs. 1999;57(4):607-31.

18. Mirtazapine Dosage Guide with Precautions - Drugs.com [Internet]. [cited 2021 Jan 13]. Available from: https://www.drugs.com/dosage/mirtazapine.html

19. Smit M, Dolman KM, Honig A. Mirtazapine in pregnancy and lactation - A systematic review. Eur Neuropsychopharmacol. 2016;26(1):126-35.

20. Gemmel M, Kokras N, Dalla C, Pawluski JL. Perinatal fluoxetine prevents the effect of pre-gestational maternal stress on $5-\mathrm{HT}$ in the PFC, but maternal stress has enduring effects on mPFC synaptic structure in offspring. Neuropharmacology. 2018;128:168-80.

21. Herlenius E, Lagercrantz H. Development of neurotransmitter systems during critical periods. Exp Neurol. 2004;190:8-21.

22. Herlenius E, Lagercrantz H. Neurotransmitters and neuromodulators during early human development. Early Hum Dev. 2001;65(1):21-37.

23. Holmes SE, Scheinost D, Finnema SJ, Naganawa M, Davis MT, DellaGioia N, et al. Lower synaptic density is associated with depression severity and network alterations. Nat Commun. 2019;10(1):1-10.

24. Xu L, Long J, Su Z, Xu B, Lin M, Chen Y, et al. Restored presynaptic synaptophysin and cholinergic inputs contribute to the protective effects of physical running on spatial memory in aged mice. Neurobiol Dis. 2019;132.

25. Bódi N, Polgár A, Kiss E, Mester, Poór G, Kéri S. Reduced volumes of the CA1 and CA4-dentate gyrus hippocampal subfields in systemic lupus erythematosus. Lupus. 2017;26(13):1378-82. 
26. Senzai Y. Function of local circuits in the hippocampal dentate gyrus-CA3 system. Vol. 140, Neuroscience Research. 2019. p. 43-52.

27. Furuse K, Ukai W, Hashimoto E, Hashiguchi H, Kigawa Y, Ishii T, et al. Antidepressant activities of escitalopram and blonanserin on prenatal and adolescent combined stress-induced depression model: Possible role of neurotrophic mechanism change in serum and nucleus accumbens. J Affect Disord. 2019;247(July 2018):97-104.

28. Bögi E, Belovičová K, Moravčíková L, Csatlósová K, Dremencov E, Lacinova L, et al. Pre-gestational stress impacts excitability of hippocampal cells in vitro and is associated with neurobehavioral alterations during adulthood. Behav Brain Res. 2019;375:112131.

29. Youssef M, Atsak P, Cardenas J, Kosmidis S, Leonardo ED, Dranovsky A. Early life stress delays hippocampal development and diminishes the adult stem cell pool in mice. Sci Rep. 2019 Dec;9(1).

30. Rayen I, van den Hove DL, Prickaerts J, Steinbusch HW, Pawluski JL. Fluoxetine during development reverses the effects of prenatal stress on depressive-like behavior and hippocampal neurogenesis in adolescence. Borlongan C V., editor. PLoS One [Internet]. 2011 Jan 1 [cited 2015 Dec 18];6(9):e24003. Available from: http://dx.plos.org/10.1371/journal.pone.0024003

32. Thion MS, Garel S. On place and time: microglia in embryonic and perinatal brain development [Internet]. Vol. 47, Current Opinion in Neurobiology. Elsevier Ltd; 2017 [cited 2020 Aug 13]. p. 121-30. Available from: https://linkinghub.elsevier.com/retrieve/pii/S0959438817301186

33. Reemst K, Noctor SC, Lucassen PJ, Hol EM. The indispensable roles of microglia and astrocytes during brain [cited 2018 Jan 15];3(1):79-83. Available from: http://www.ncbi.nlm.nih.gov/pubmed/118862 
[Internet]. 2008 Mar [cited 2014 Jul 14];22(3):659-61. Available from:

37. Sotocinal SG, Sorge RE, Zaloum A, Tuttle AH, Martin L, Wieskopf JS, et al. The Rat Grimace Scale: A partially automated method for quantifying pain in the laboratory rat via facial expressions. Mol Pain [Internet]. 2011 [cited 2021 Jun 16];7. Available from: https://pubmed.ncbi.nlm.nih.gov/21801409/

38. Conrad CD, Galea LAM, Kuroda Y, McEwen BS. Chronic stress impairs rat spatial memory on the Y maze,

39. Harquin Simplice F, David Emery T, Hervé Hervé NA. Enhancing spatial memory: Anxiolytic and antidepressant effects of Tapinanthus dodoneifolius (DC) Danser in mice. Neurol Res Int. 2014;2014.

40. Kraeuter A, Guest PC. Chapter 10. 2019;1916:105-11.

41. Whittaker AL, Howarth GS. Use of spontaneous behaviour measures to assess pain in laboratory rats and mice: How are we progressing $\alpha$ [Internet]. Vol. 151, Applied Animal Behaviour Science. 2014 [cited 2020 Oct 30]. p. 1-12. Available from: https://linkinghub.elsevier.com/retrieve/pii/S0168159113002591

42. Leung VSY, Benoit-Biancamano MO, Pang DSJ. Performance of behavioral assays: The Rat Grimace Scale,

43. Schneider LE, Henley KY, Turner OA, Pat B, Niedzielko TL, Floyd CL. Application of the Rat Grimace Scale as a Marker of Supraspinal Pain Sensation after Cervical Spinal Cord Injury. J Neurotrauma [Internet]. 2017 Nov 1 [cited 2021 May 18];34(21):2982-93. Available from: https://pubmed.ncbi.nlm.nih.gov/27998207/

44. Lévy F. Neuroendocrine control of maternal behavior in non-human and human mammals. Ann Endocrinol (Paris) [Internet]. 2016 Jun 1 [cited 2021 May 18];77(2):114-25. Available from: https://linkinghub.elsevier.com/retrieve/pii/S0003426616300178

45. Weinstock M. Prenatal stressors in rodents: Effects on behavior. Vol. 6, Neurobiology of Stress. Elsevier Inc; 
Pharmacol Biochem Behav [Internet]. 2014 [cited 2021 May 18];117:25-33. Available from: /pmc/articles/PMC4034582/

48. Gemmel M, Bögi E, Ragan C, Hazlett M, Dubovicky M, van den Hove DL, et al. Perinatal selective serotonin reuptake inhibitor medication (SSRI) effects on social behaviors, neurodevelopment and the epigenome [Internet]. Vol. 85, Neuroscience and Biobehavioral Reviews. Elsevier Ltd; 2018 [cited 2021 May 18]. p. 102-16. Available from: https://linkinghub.elsevier.com/retrieve/pii/S0149763417300763

49. Belovičová K, Šimončičová E, Noguera MV, Dubovický M, Bögi E. Long-term effects of pre-gestational stress and perinatal venlafaxine treatment on neurobehavioral development of female offspring. Behav Brain Res [Internet]. 2021 Feb 1 [cited 2021 May 18];398. Available from:

https://pubmed.ncbi.nlm.nih.gov/33017639/

50. Gemmel M, Harmeyer D, Bögi E, Fillet M, Hill LA, Hammond GL, et al. Perinatal fluoxetine increases hippocampal neurogenesis and reverses the lasting effects of pre-gestational stress on serum corticosterone, but not on maternal behavior, in the rat dam. Behav Brain Res [Internet]. 2018 Feb 26 [cited 2018 Feb 13];339:222-31. Available from: http://www.ncbi.nlm.nih.gov/pubmed/29203333

51. Lian S, Xu B, Wang D, Wang L, Li W, Yao R, et al. Possible mechanisms of prenatal cold stress inducedanxiety-like behavior depression in offspring rats. Behav Brain Res. 2019;359(August 2018):304-11.

52. Vásquez F de JJ, Guerrero DM, Osornio MR, Osornio MDCR, Suárez SO, Retana-márquez S. Decreased serotonin content and release in the ventral hippocampus of prenatally stressed male rats in response to forced swim test. Acta Neurobiol Exp (Wars). 2020;80(4):331-43.

53. Miyagawa K, Tsuji M, Fujimori K, Saito Y, Takeda H. Prenatal stress induces anxiety-like behavior together with the disruption of central serotonin neurons in mice. Neurosci Res. 2011 May;70(1):111-7.

54. Belovicova K, Bogi E, Csatlosova K, Dubovicky M. Animal tests for anxiety-like and depression-like behavior in rats. Interdiscip Toxicol [Internet]. 2017 Sep 1 [cited 2021 Jun 16];10(1):40-3. Available from: /pmc/articles/PMC6096862/

55. Sengupta P. The laboratory rat: Relating its age with human's [Internet]. Vol. 4, International Journal of Preventive Medicine. Wolters Kluwer -- Medknow Publications; 2013 [cited 2021 Jun 16]. p. 624-30. Available from: /pmc/articles/PMC3733029/

56. Grundwald NJ, Brunton PJ. Psychoneuroendocrinology Prenatal stress programs neuroendocrine stress responses and affective behaviors in second generation rats in a sex-dependent manner. Psychoneuroendocrinology. 2015;62:204-16.

57. Hutchison SM, Masse LC, Pawluski JL, Tim F. Perinatal selective serotonin reuptake inhibitor (SSRI) and 
other antidepressant exposure effects on anxiety and depressive behaviors in offspring: A review of findings in humans and rodent models Sarah. Reprod Toxicol. 2020;

58. Millard SJ, Lum JS, Fernandez F, Newell KA. Perinatal exposure to fluoxetine increases anxiety- and depressive-like behaviours and alters glutamatergic markers in the prefrontal cortex and hippocampus of male adolescent rats : A comparison between Sprague-Dawley rats and the Wistar-Kyoto rat model . 2019;

59. Brunton PJ, Russell JA. Prenatal Social Stress in the Rat Programmes Neuroendocrine and Behavioural Responses to Stress in the Adult Offspring : Sex-Specific Effects Neuroendocrinology. 2010;(10):258-71.

60. Rauggi R, Cassanelli A, Raone A, Tagliamonte A, Gambarana C. Study of mirtazapine antidepressant effects in rats. Int J Neuropsychopharmacol. 2005;8(3):369-79.

61. Sahoo J, Pattnaik AK, Mishra N. Behavioral and developmental changes in rats with prenatal exposure of mirtazapine. Sci Pharm. 2010;78(3):451-63.

62. Oyola MG, Handa RJ. Hypothalamic-pituitary-adrenal and hypothalamic-pituitary-gonadal axes: sex differences in regulation of stress responsivity. Stress. 2017;20(5):476-94.

63. Jezova D, Balagova L, Chmelova M, Hlavacova N. Classical Steroids in a New Fashion : Focus on

64. Porsolt. BEHAVIOURAL DESPAIR IN RATS : A NEW MODEL SENSITIVE TO ANTIDEPRESSANT TREATMENTS. $1977 ; 47$

65. Wisłowska-Stanek A, Płaźnik A, Kołosowska K, Skórzewska A, Turzyńska D, Liguz-Lęcznar M, et al. test. Behav Brain Res. 2019;359(June 2018):181-9. Res. 2019;364(February):1-10.

607 67. Yang R, Zhang MQ, Xue Y, Yang R, Tang MM. Dietary of n-3 polyunsaturated fatty acids influence neurotransmitter systems of rats exposed to unpredictable chronic mild stress. Behav Brain Res. 2019;376(April):112172. predicts immobility behavior in the forced swim test: Effects of a chronic treatment with tianeptine. Brain Res [Internet]. 2003 Nov 7 [cited 2021 May 20];989(2):246-51. Available from: 
69. Ceniceros LC, Capitanio JP, Kinnally EL. Prenatal Relocation Stress Enhances Resilience Under Challenge in Infant Rhesus Macaques. Front Behav Neurosci [Internet]. 2021 Mar 29 [cited 2021 May 20];15. Available from: https://pubmed.ncbi.nlm.nih.gov/33854420/

70. Serpeloni F, Radtke KM, Hecker T, Sill J, Vukojevic V, De Assis SG, et al. Does prenatal stress shape postnatal resilience? An epigenome-wide study on violence and mental health in humans. Front Genet [Internet]. 2019 [cited 2021 May 20];10(MAR). Available from: https://pubmed.ncbi.nlm.nih.gov/31040859/

71. Oosterhof CA, El Mansari M, Merali Z, Blier P. Altered monoamine system activities after prenatal and adult stress: A role for stress resilience? Brain Res [Internet]. 2016 Jul 1 [cited 2021 May 20];1642:409-18. Available from: https://pubmed.ncbi.nlm.nih.gov/27086968/

72. Detke MJ, Rickels M, Lucki I. Active behaviors in the rat forced swimming test differentially produced by serotonergic and noradrenergic antidepressants. Psychopharmacology (Berl) [Internet]. 1995 Sep [cited 2021 Jun 16];121(1):66-72. Available from: https://link.springer.com/article/10.1007/BF02245592

73. Brummelte S, Lieblich SE, Galea LAM. Gestational and postpartum corticosterone exposure to the dam affects behavioral and endocrine outcome of the offspring in a sexually-dimorphic manner. Neuropharmacology. 2012;62(1):406-18.

74. Sprowles JLN, Hufgard JR, Gutierrez A, Bailey RA, Jablonski SA, Williams MT, et al. Differential effects of perinatal exposure to antidepressants on learning and memory, acoustic startle, anxiety, and open-field activity in Sprague-Dawley rats. Int J Dev Neurosci [Internet]. 2017 Oct 1 [cited 2021 May 25];61(1):92111. Available from: https://onlinelibrary.wiley.com/doi/abs/10.1016/j.ijdevneu.2017.06.004

634 75. Rosenqvist MA, Sjölander A, Ystrom E, Larsson H, Reichborn-Kjennerud T. Adverse family life events during pregnancy and ADHD symptoms in five-year-old offspring. J Child Psychol Psychiatry Allied Discip [Internet]. 2019 Jun 1 [cited 2021 Jun 21];60(6):665-75. Available from:

76. Simons SSH, Zijlmans MAC, Cillessen AHN, de Weerth C. Maternal prenatal and early postnatal distress and child stress responses at age 6. Stress [Internet]. 2019 Nov 2 [cited 2021 Jun 21];22(6):654-63. Available from: https://pubmed.ncbi.nlm.nih.gov/31092104/

641 77. Schepanski S, Buss C, Hanganu-Opatz IL, Arck PC. Prenatal Immune and Endocrine Modulators of Offspring's Brain Development and Cognitive Functions Later in Life [Internet]. Vol. 9, Frontiers in immunology. NLM (Medline); 2018 [cited 2021 Jun 21]. p. 2186. Available from: 
78. Richetto J, Riva MA. Prenatal maternal factors in the development of cognitive impairments in the offspring. J Reprod Immunol. 2014;104-105:20-5.

79. Deminière JM, Piazza PV, Guegan G, Abrous N, Maccari S, Moal M Le, et al. Increased locomotor response to novelty and propensity to intravenous amphetamine self-administration in adult offspring of stressed mothers. Brain Res. 1992;586(1):135-9.

80. Zuena AR, Mairesse J, Casolini P, Cinque C, Alemà GS, Morley-Fletcher S, et al. Prenatal restraint stress generates two distinct behavioral and neurochemical profiles in male and female rats. PLoS One. $2008 ; 3(5)$.

81. Gemmel M, Hazlett M, Bögi E, De Lacalle S, Hill LA, Kokras N, et al. Perinatal fluoxetine effects on social play, the HPA system, and hippocampal plasticity in pre-adolescent male and female rats: Interactions with pre-gestational maternal stress. Psychoneuroendocrinology [Internet]. 2017 Oct [cited 2018 Feb 13];84:159-71. Available from: http://www.ncbi.nlm.nih.gov/pubmed/28735226

82. Conrad CD, Grote KA, Hobbs RJ, Ferayorni A. Sex differences in spatial and non-spatial Y-maze performance after chronic stress. Neurobiol Learn Mem. 2003;79(1):32-40.

83. Burke HM, Robinson CM, Wentz B, McKay J, Dexter KW, Pisansky JM, et al. Sex-specific impairment of spatial memory in rats following a reminder of predator stress. Stress. 2013;16(4):469-76.

84. Armario A, Nadal R. Individual differences and the characterization of animal models of psychopathology: A strong challenge and a good opportunity. Front Pharmacol. 2013;4 NOV(November):1-13.

85. Sprowles JLN, Hufgard JR, Gutierrez A, Bailey RA, Jablonski SA, Williams MT, et al. Perinatal exposure to the selective serotonin reuptake inhibitor citalopram alters spatial learning and memory, anxiety, depression, and startle in Sprague-Dawley rats. Int J Dev Neurosci [Internet]. 2016 Nov [cited 2018 Feb 12];54:39-52. Available from: http://linkinghub.elsevier.com/retrieve/pii/S0736574816301575

86. Jankord R, Solomon MB, Albertz J, Flak JN, Zhang R, Herman JP. Stress vulnerability during adolescent development in rats. Endocrinology. 2011;152(2):629-38.

87. Eiland L, Romeo RD. Stress and the developing adolescent brain. Neuroscience. 2013;249(212):162-71.

88. Llorente R, Miguel-Blanco C, Aisa B, Lachize S, Borcel E, Meijer OC, et al. Long Term Sex-Dependent Psychoneuroendocrine Effects of Maternal Deprivation and Juvenile Unpredictable Stress in Rats. J Neuroendocrinol. 2011;23(4):329-44.

89. Calhoun ME, Jucker M, Martin LJ, Thinakaran G, Price DL, Mouton PR. Comparative evaluation of synaptophysin-based methods for quantification of synapses. J Neurocytol [Internet]. 1996 [cited 2021 
676

677

678

679

680

681

682

683

684

685

686

687

688

689

690

691

692 mirtazapine groups.

701

Figure 5. Percentage of distance travelled in individual arms of elevated plus maze by juvenile animals. (A) open arm

90. Yagi S, Galea LAM. Sex differences in hippocampal cognition and neurogenesis [Internet]. Vol. 44, Neuropsychopharmacology. Nature Publishing Group; 2019 [cited 2021 May 25]. p. 200-13. Available from: https://doi.org/10.1038/s41386-018-0208-4

91. Afadlal S, Polaboon N, Surakul P, Govitrapong P, Jutapakdeegul N. Prenatal stress alters presynaptic marker proteins in the hippocampus of rat pups. Neurosci Lett. 2010;470(1):24-7.

92. Biala YN, Bogoch Y, Bejar C, Linial M, Weinstock M. Prenatal stress diminishes gender differences in behavior and in expression of hippocampal synaptic genes and proteins in rats. Hippocampus.

2011;21(10):1114-25.

93. Gemmel M, Rayen I, van Donkelaar E, Loftus T, Steinbusch HW, Kokras N, et al. Gestational stress and fluoxetine treatment differentially affect plasticity, methylation and serotonin levels in the PFC and hippocampus of rat dams. Neuroscience. 2016 Jul;327:32-43.

94. Carvalho-Netto EF, Myers B, Jones K, Solomon MB, Herman JP. Sex differences in synaptic plasticity in stress-responsive brain regions following chronic variable stress. Physiol Behav. 2011;104(2):242-7.

95. Cui Y, Cao K, Lin H, Cui S, Shen C, Wen W, et al. Early-Life Stress Induces Depression-Like Behavior and Synaptic-Plasticity Changes in a Maternal Separation Rat Model: Gender Difference and Metabolomics Study. Front Pharmacol. 2020;11(February):1-13.

\section{FIGURE CAPTIONS}

Figure 1. Chemical structure of mirtazapine.

Figure 2. Schedule of the experiment. G- gestation day; PP-post-partum day; EPM- elevated plus maze; FST- forced swim test.

Figure 3. Grimace scale test. Data represent mean \pm SEM. $n=6-7$ animals/group.

Figure 4. Maternal behavior. (A) total time spent nursing, (B) percentage of passive nursing and blanket nursing out of total time spent nursing. Data represent mean \pm SEM. $n=6-10$ animals/group. ${ }^{*} p \leq 0.05 ; m$-compared to both distance, (B) closed arm distance. Data represent mean \pm SEM. $n=7-8$ animals/group. MIR- mirtazapine; ${ }^{*} p \leq 0.05$. 
703 Figure 6. Elevated plus maze of adolescent offspring. (A) total distance travelled, (B) open arm time percentage, (C)

704 closed arm percentage. Data represent mean \pm SEM. $n=7-10$ animals/group. $m$ - compared to both mirtazapine

705 groups; s- compared to stress $\times$ vehicle group; ns- compared to both non-stress groups; + - marginal significance;

$706 \quad * p \leq 0.05$

707 Figure 7. Forced swim test of adolescent offspring. (A) time spent floating, (B) time spent swimming, (C) time spent

708 climbing. $n=7-11$ animals/group. ${ }^{* *} \mathrm{p} \leq 0.01$.

709 Figure 8. Y-maze of adolescent offspring. (A) total distance travelled, (B) percentage of spontaneous alterations.

710 Data represent mean \pm SEM. $n=5-8$ animals/group. a- compared to non-stress $\times$ mirtazapine, $b$ - compared to stress

$711 \times$ vehicle, c-compared to stress $\times$ mirtazapine, +- marginal significance, ${ }^{*} p \leq 0.05,{ }^{* *} p \leq 0.01$.

712 Figure 9. Optical density of synaptophysin in hippocampus. (A) Ca3 area, (B) Ca4 area, (C) dentate gyrus area. Data

713 represent mean \pm SEM. $n=5-8$. 
bioRxiv preprint doi: hittps://doi.org/10.1101/2021.08.04.455108; t version posted August 4, 2021. The copyright holder for this preprint
(which was not certified by peer review) is the authorffunder, who has vranted bioRxiv a license to display the preprint in perpetuity. It is made available under aCC-BY 0 International license.
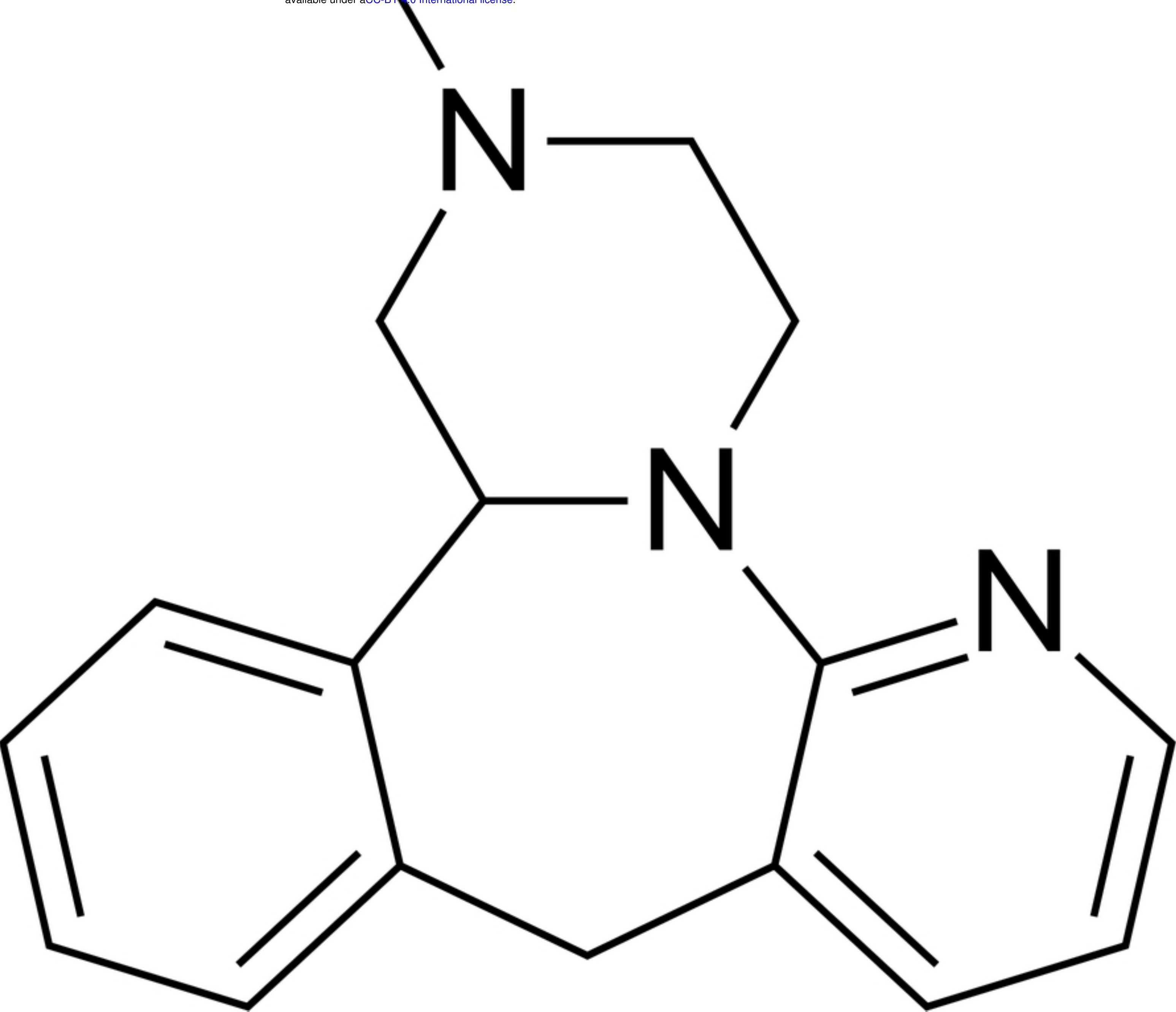


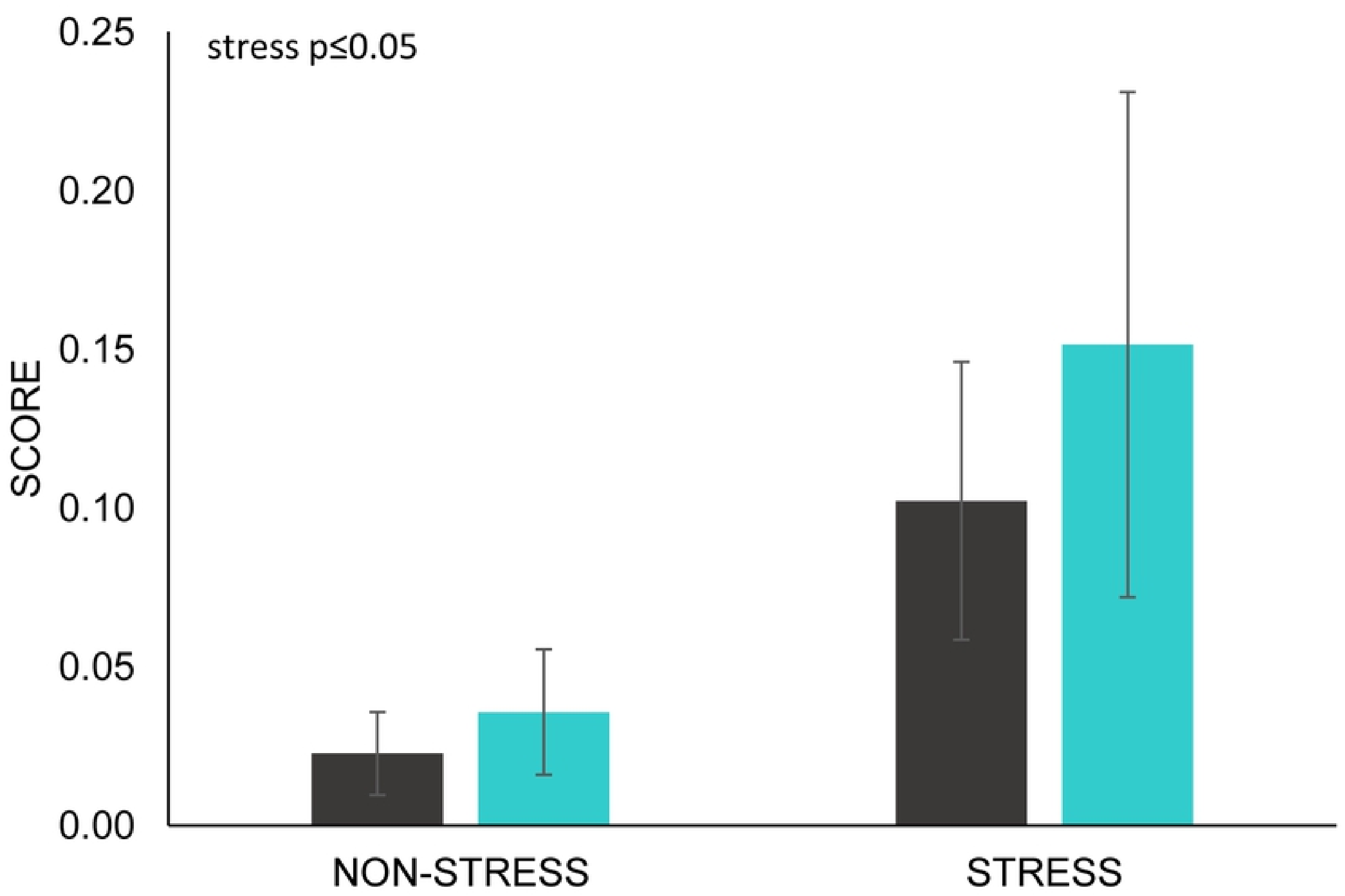

-VEHICLE MIRTAZAPINE 
A

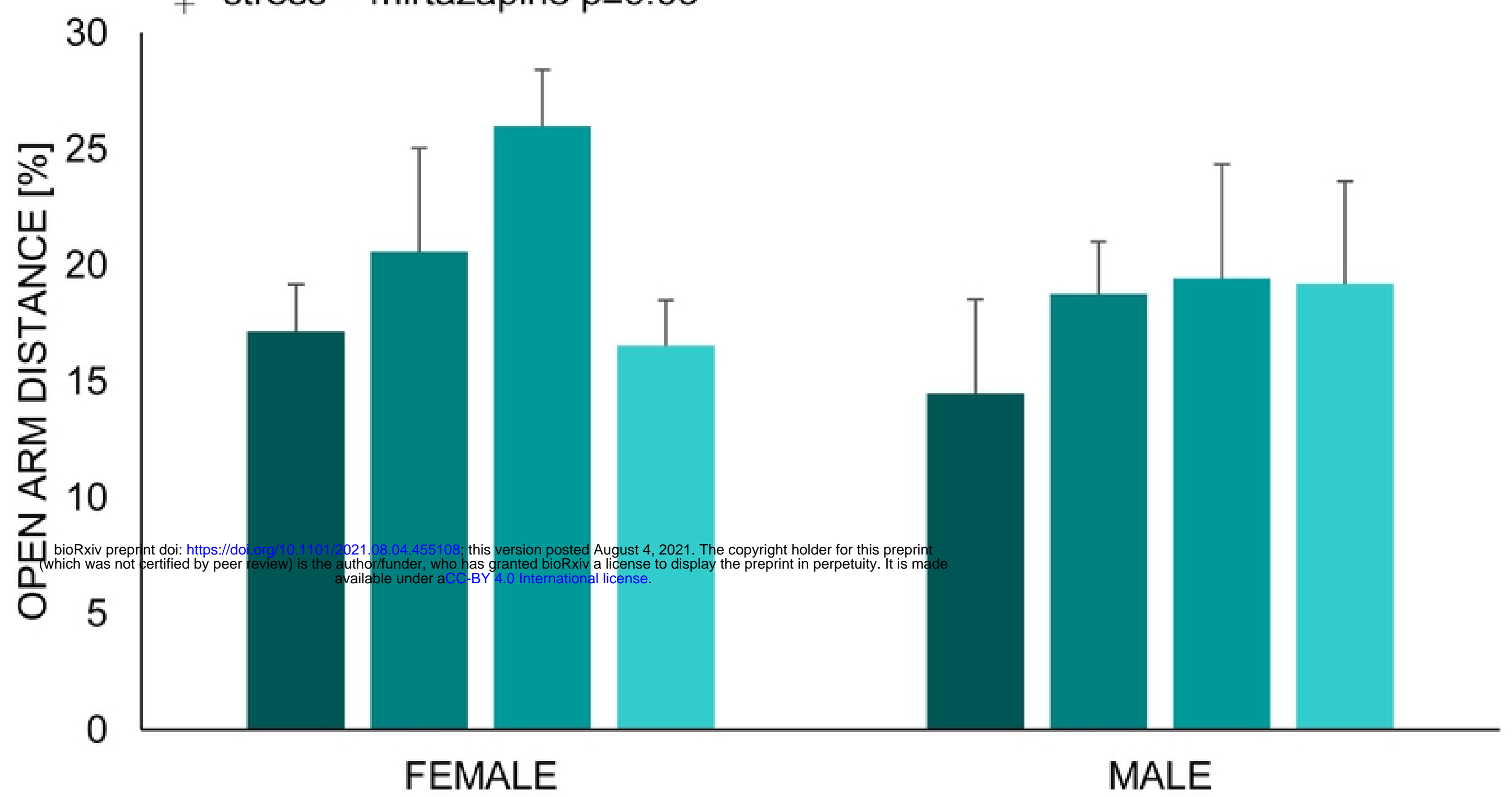

-NON-STRESS+VEHICLE $₫$ NON-STRESS+MIR $\approx S T R E S S+V E H I C L E ~ \backsim S T R E S S+M I R$

B

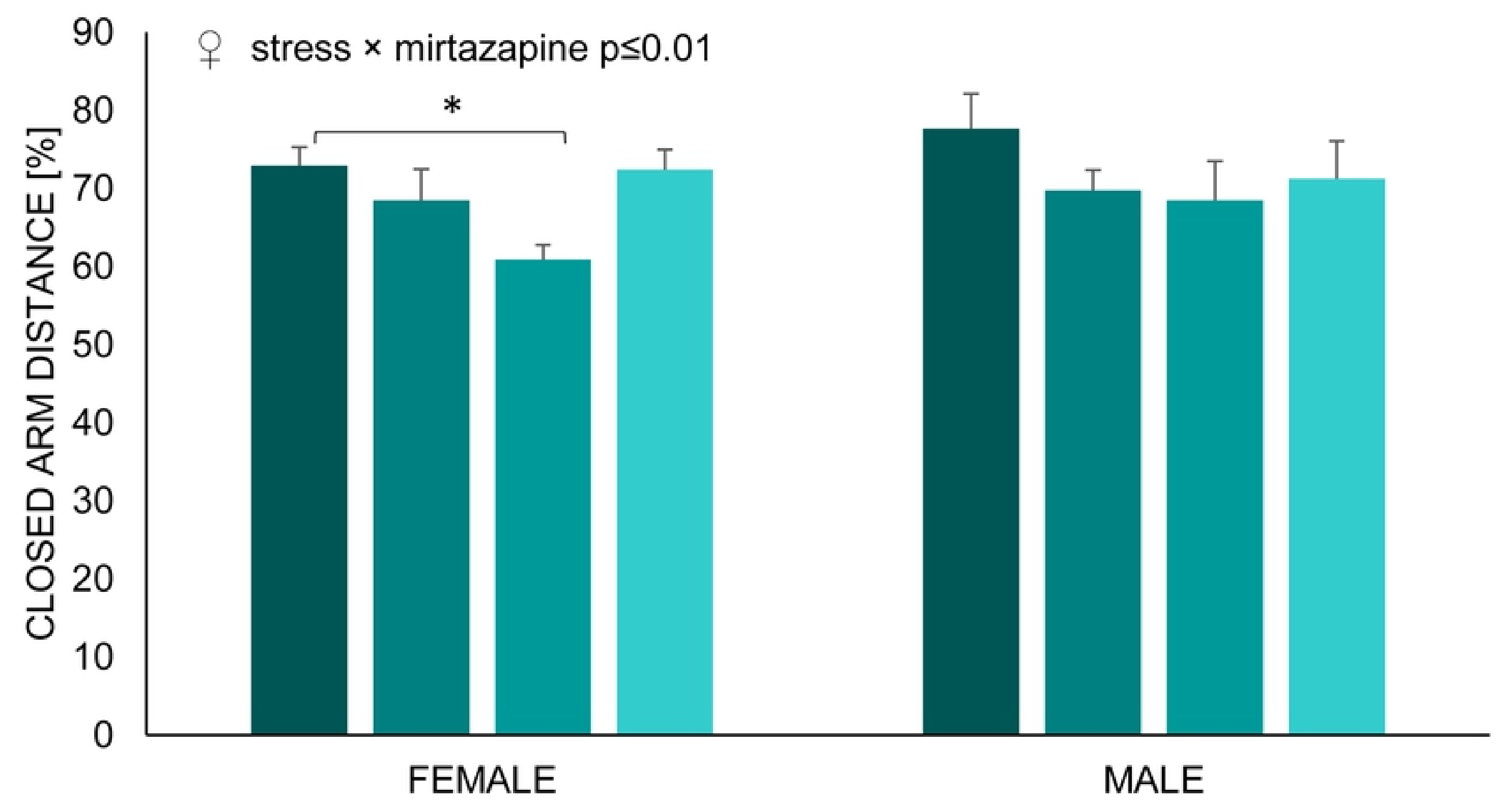

-NON-STRESS+VEHICLE $\approx$ NON-STRESS+MIR $\approx$ STRESS+VEHICLE $₫$ STRESS+MIR 


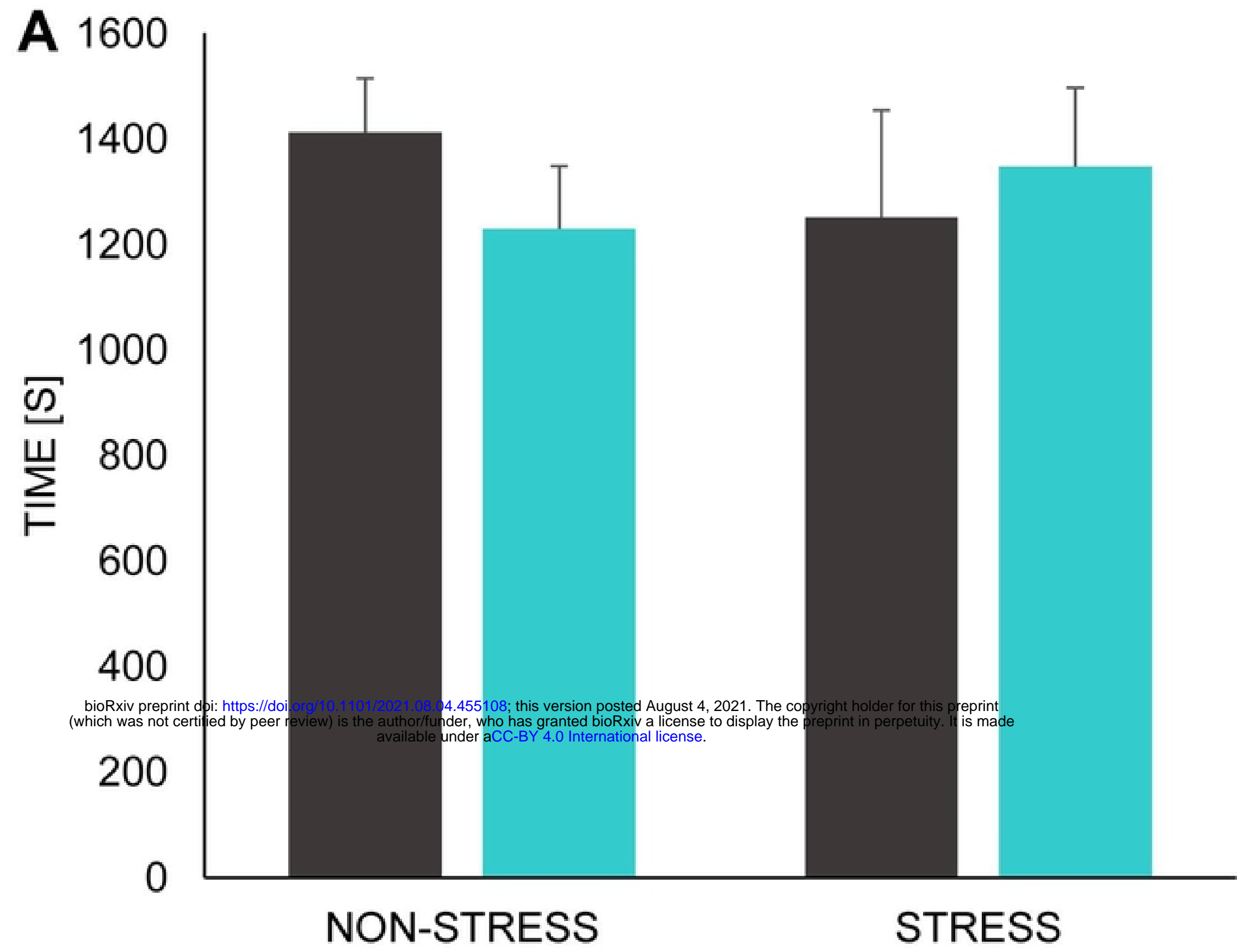

-VEHICULUM MIRTAZAPINE

B

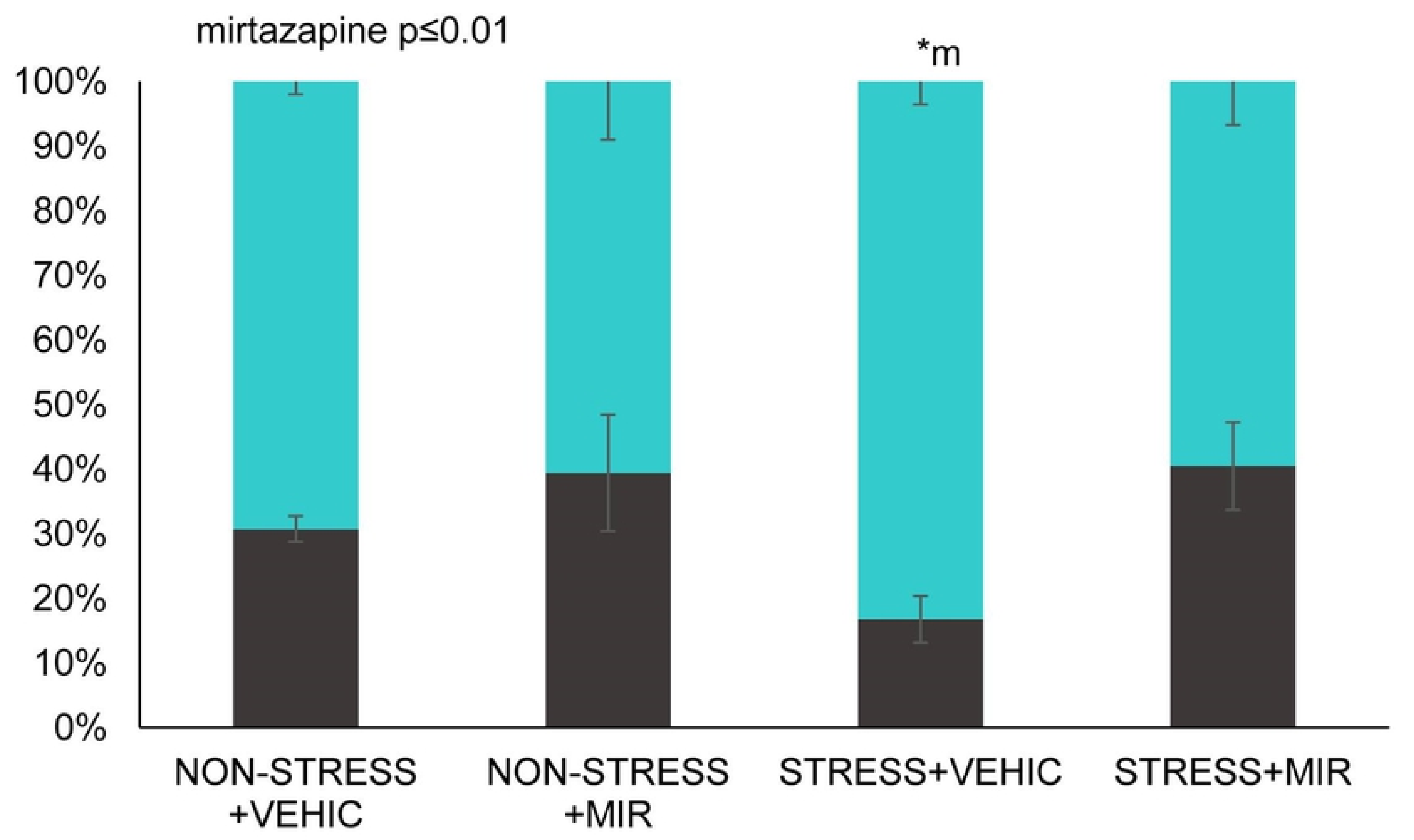




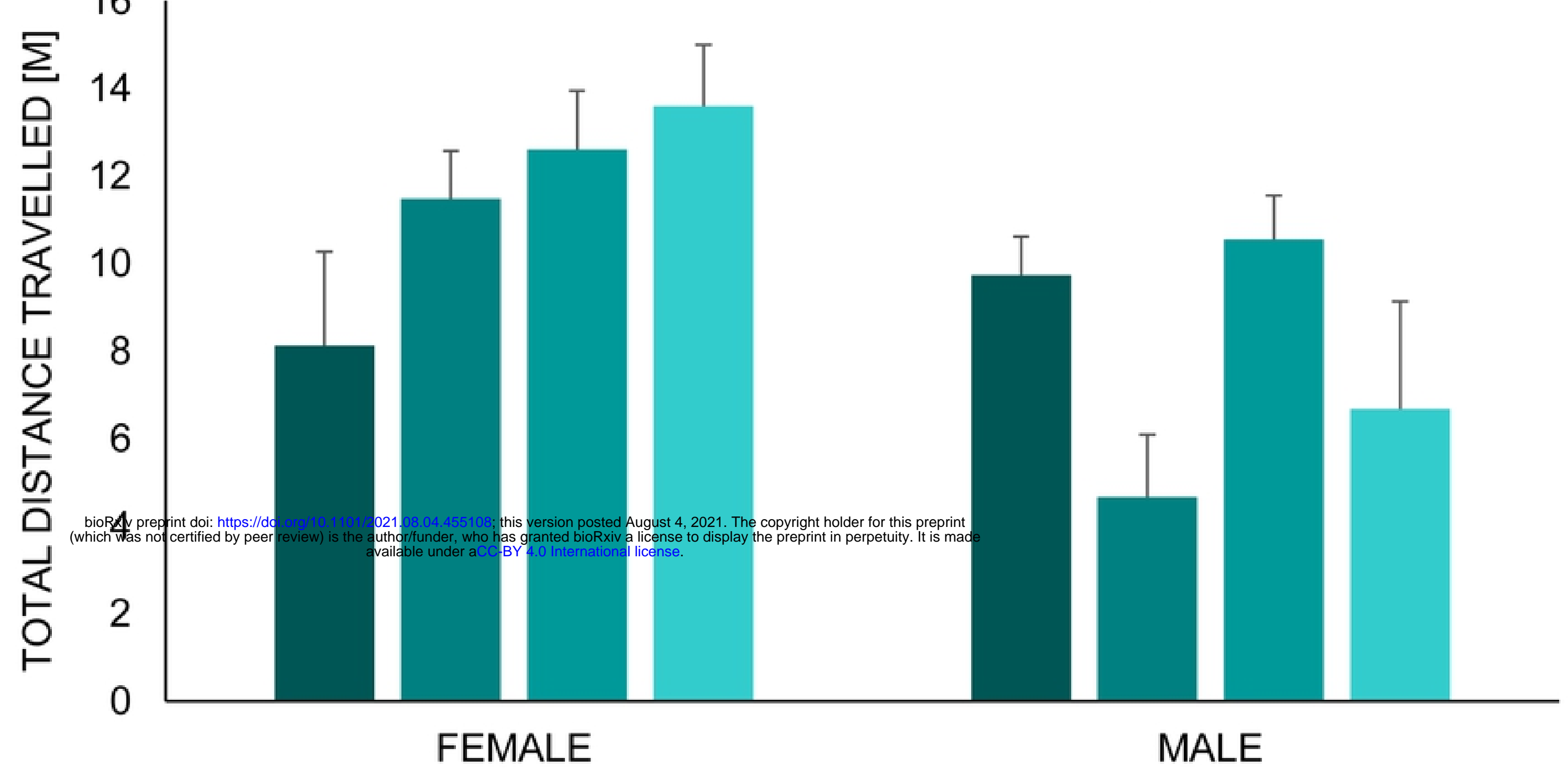

$\because$ NON-STRESS+VEHICLE $\backsim$ NON-STRESS+MIR $\approx S T R E S S+V E H I C L E \backsim S T R E S S+M I R$

B

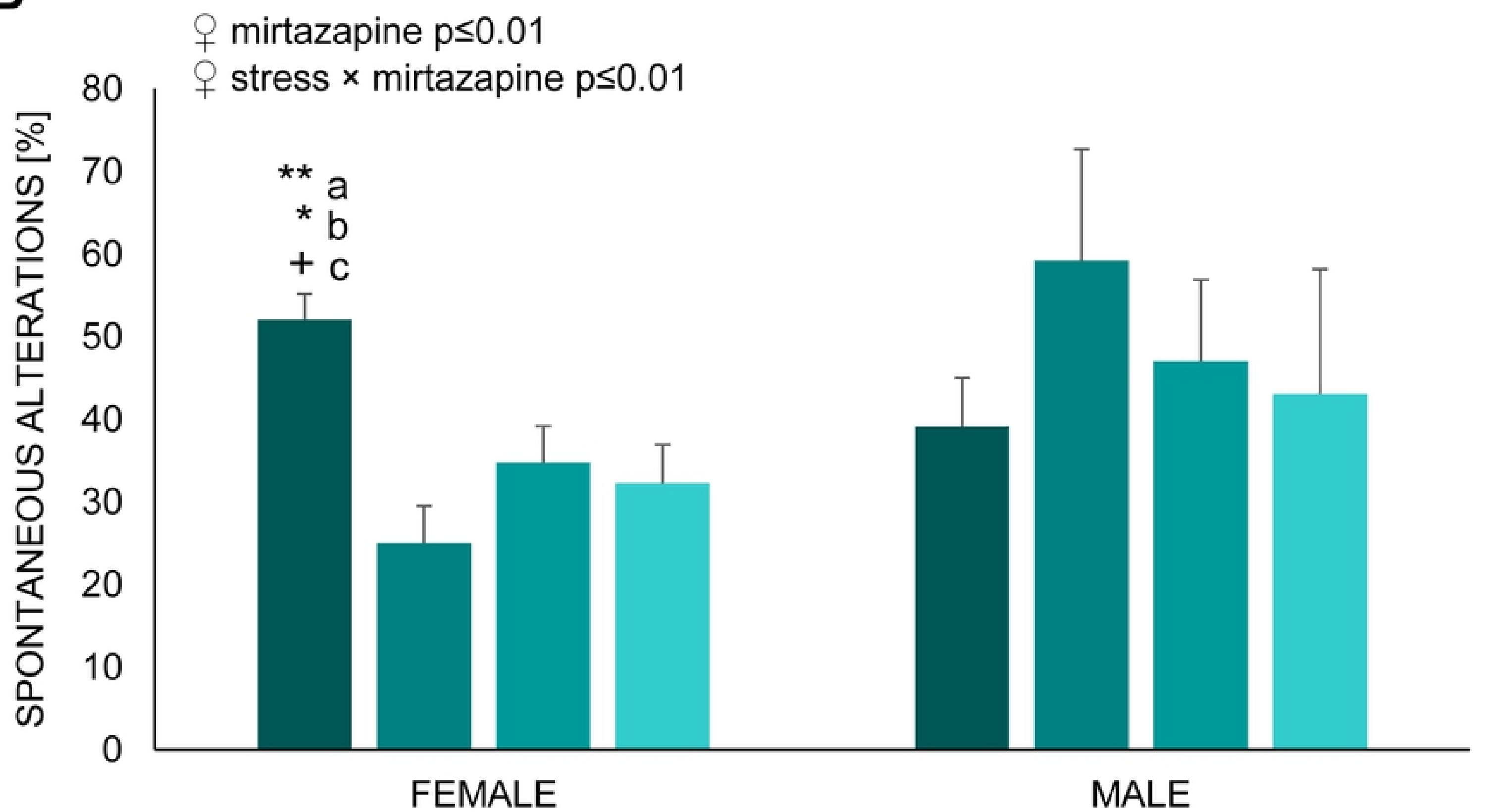

-NON-STRESS+VEHICLE $=$ NON-STRESS+MIR $=S T R E S S+V E H I C L E ~=S T R E S S+M I R$ 
